\title{
Ageing, old age and media: Critical appraisal of knowledge practices in academic research
}

\author{
By SARA Mosberg IVERSEN ${ }^{1} \mathcal{E}$ Monika WILIŃSKA ${ }^{2}$
}

\begin{abstract}
This interpretative literature review discusses research published between 2000 and 2015 that focuses on the media representation of older adults. The key objective is to offer a critical discussion on the knowledge and assumptions underlying such studies. Specifically, the review examines how old age and media, respectively, are conceptualised in the research and the consequence this has for further research in the fields of ageing and media studies. The main finding from this review is that a large part of the research appears to say nothing about what old age and media are, as it either entirely fails to discuss what is meant by these terms or relies on common sense notions. The review concludes that research on older age and media suffers from a lack of dialogue over disciplinary borders and that this issue needs to be remedied. Likewise, for research to move on, it is imperative to take a more reflexive stance on the topics in order to avoid simplistic notions of both ageing and media.

Keywords: ageing, gerontology, knowledge practices, literature review, media, media studies, old age.

${ }^{1}$ Sara Mosberg Iversen, Department for the Study of Culture, Media Studies, University of Southern Denmark, Odense, Denmark

${ }^{2}$ Monika Wilińska, Department of Social Work, School of Health and Welfare, Jönköping University, Jönköping, Sweden
\end{abstract}


International Journal of Ageing and Later Life

\section{Introduction}

It is widely recognised that the relationship between ageing, old age and media is a strained one. Media texts and institutions are often seen as some of the main forces responsible for reproducing stereotypical images of ageing and old age, thereby contributing to a solidification of socially and culturally constructs about later life. Gullette, discussing the concept of age in contemporary societies, summarises her arguments as follows: "We are aged by culture" (2004: 12), and media may play an important role in that process. Moreover, the overall media landscape has traditionally been regarded as a space that does not make adequate room for ageing and old age (Syvertsen 2010). The focus on older adults within media-oriented research is increasing, however, and various forms of media are increasingly addressed within fields that are concerned with later life. This research emerges from the intersection of Gerontology and Media and Communication Studies, two disciplines that have not traditionally entered into dialogue with each other. Yet, in order to develop and heighten the quality of research endeavours that address the complex relationship between aging, old age and media, dialogue over disciplinary borders is necessary. The strengthening of such exchanges is particularly important with regard to the underlying assumptions that inform research. This article aims to provide a starting point for such dialogue by examining the assumptions about media and old age that inform the current research into media representations of ageing and old age. Specifically, the article focuses on knowledge creation about ageing, old age and media as produced within published academic work that examines media representations of older adults.

We position this article alongside earlier literature reviews concerned with different aspects of media representations of older adults. These include studies of American television and older adult viewers from the 1970s onwards (Douglas \& Buck 2009), advertising depicting older adults (Zhang et al. 2006), the portrayal of older employees in mass media (van Selm \& van der Heijden 2014) and a systematic review that focuses on the key findings from studies examining images of ageing in mass media in Western and Asian countries (Bai 2014). Our study aims to offer a critical reading of the knowledge produced about ageing, old age and media rather than reviewing the ways in which older adults are 
Ageing, old age and media

represented in media. To this end, we are guided by the following research questions: How are ageing, old age and media understood in the examined research, and which issues regarding media representation of older adults are problematized in the analysed articles?

Firstly, the understanding of knowledge underlying the article is discussed, followed by methodological reflections. Then, the reviewed articles are analysed and discussed in terms of three constructions: (1) the construction of old age and ageing, (2) the construction of media and (3) the construction of problematic representations.

\section{The Question of Knowledge Construction}

In their seminal work on the social construction of reality, Berger and Luckmann (1989) postulated a shift in the sociology of knowledge, which once took knowledge about everyday life for granted. Instead, they argued, knowledge about social reality does not exist as such; it is constructed here and now. Since then, social constructionism has become one of the key paradigms embraced by social scientists in their quest to understand the world. Social constructionism is founded on the following guidelines: any knowledge that is taken for granted should be questioned, the process of understanding is embedded in the context and the linkages between knowledge and social processes and actions are mutually reinforcing (Burr 2007; Jørgensen \& Phillips 2010). Within this paradigm, the questions of truth and scientific accuracy in reflecting the exact image of reality become less important. Instead, the process of knowledge production/construction and its links with the social reality have come to the forefront. Knowledge is used more often in the plural form than in the singular; there are diverse and multiple ways of knowing and also various knowledges that co-exist. This gives rise to the concept of knowledge as culture, where culture does not entail a system of shared meaning but emphasises a range of cultural practices that shape our reality (McCarthy 1996). Science is only one of the many cultural practices entangled in this construction (Pascale 2011). Practices grow out of specific locations that influence their type and content. Consequently, knowledge is always located and situated (Haraway 1991; Lykke 2010). This also holds true for knowledge about ageing, old age and media. 
International Journal of Ageing and Later Life

Following on from that, notions of ageing and old age are never straightforward or given. After all, ageing is a life-long process that begins the very day someone is born. Likewise, what at any given time is understood as "old age" is highly context-dependent, including when someone is understood to be "old" rather than, for instance, "an adult" or "young." We emphasise that not only who is considered "older" or "old," but even what is meant by these terms, is a matter of social construction (Hazan 1994). In many contemporary societies, ageing is equated with decline and misery (Gullette 2004), and old age is seen as a type of trap that spreads around our social and cultural environments (Hazan 1994). This trap presents old age as a fearsome and frightening disease, and it depicts old people as having no gender, race, religion, class, etc. (Cruikshank 2003). The development of gerontology - the science of age and ageing - has greatly contributed to such understandings of old age (Cohen 1992). In its attempt to understand old age and ageing, gerontology has successfully constructed a discipline around the problem of old age, as Katz (1996) argues. In particular, the development of scientific knowledge about ageing and old age has greatly contributed to the medicalisation of old age, which began to be seen as a problem that required a solution (e.g. Green 1993; Katz 1996; Powell 2001, 2006). Thus, the creation of academic knowledge can be regarded as yet another important practice that, like media institutions, texts and technologies, makes age and ageing socially visible as well as relevant and important to the ways in which we perceive ourselves, others and the social reality in which we live. By extension, old age is something that is done, and this doing involves the processes of categorising, organising and ranking according to socially and culturally defined imaginaries.

\section{Methodological Approach}

This article is based on a critical reading of a body of scholarship conducted from the perspective of social constructionism. Our objective was neither to systematise nor synthesise the existing research on ageing, old age and media, but rather to offer a critical commentary on the types of knowledge and assumptions underlying such studies. Responding to the critique regarding the focus and quality of qualitative literature reviews 
Ageing, old age and media

(Baumeister \& Leary 1997; Jones 2004; Thorne 2017; Weed 2006, 2008), we therefore approach the reviewed articles as we would any other type of qualitative data. The 186 articles under review here are therefore approached as 186 individual voices that give us insights into the type of knowledge that is being created about ageing, old age and media.

For the purpose of this study, we collected 186 research articles that were identified via searches in the following databases: Academic Search Premier, Communication Source, SOCindex and Scopus (Social Sciences). The criteria for inclusion were that the articles should be in English, must have been published between 2000 and 2015 in scholarly, peer-reviewed journals and focus primarily on the media representation of older adults. Relevant articles were found via a combination of two sets of search terms. The first set of search terms included "ageing," "old age," "old men," "older people" and "old women." These were combined with a second set of search terms: "advertising," "film," "digital media," "media discourse," "media images," "media representation," "news," "newspapers," "online discourse," "radio" and "television." These searches resulted in more than 3000 hits (of which a large number of items were duplicates between the databases) that were filtered manually for relevancy by the authors. Through this process, the number of potentially relevant papers was reduced to just over 400 articles that were read and filtered yet again against the inclusion criteria, which means that, for example, review articles were excluded. This resulted in the final sample of 186 articles.

To address our research questions, we conducted analyses of key discourses in the articles under study, that is, the particular ways in which understandings of the world are made to appear true, natural and given. Unlike discourse analysis and its focus on how people use discourses, analysis of discourses focuses on showing how discourses constitute people (Bacchi 2005) or other objects of inquiry. The question underlying such analysis concerns the type of discourses that can be recognised in the studied material. Its main objective is "to describe, understand, interpret and evaluate carefully constructed objects of investigation" (Howarth 2000: 139). Overall, the analysis of discourse may be seen as an investigation into the frames of thinking and doing that are exhibited by various social actors who operate in particular times and spaces. In this article, the authors of reviewed studies were seen as such social actors and it is 
International Journal of Ageing and Later Life

their ways of framing concepts, such as ageing, old age and media that our analysis focuses on. Thus, rather than re-analysing media discourses reported in the reviewed articles, we instead analysed how those different media representations were approached, critiqued and discussed by the authors. In the process of analysis, we thus examined the theoretical reference points used to explain media and old age, study design with a particular attention paid to inclusion/exclusion criteria and the discussion of results as advanced by the authors of reviewed articles. We also considered the types of problems and concerns regarding the representation of ageing and old age in the media that are raised in the analysed articles.

\section{Constructing Knowledge about Ageing and Old Age}

In the reviewed literature, we distinguish two main perspectives taken when establishing the research focus on ageing and old age: (1) a chronological measurement of age, which is often based on appearance and activities, and (2) a notion of ageing as socially and culturally constructed. Note that within both categories, the degree to which a reflexive stance is taken towards these assessments of age varies. Moreover, a number of articles do not make any theoretical or conceptual points at all about "older adults" or "old age," but apparently take it as a given (e.g. Aday \& Austin 2000; Estrada et al. 2010; Hine 2011; Lee et al. 2006; Zhang et al. 2008; Zordan 2010).

A chronological measure is the most common way to establish "oldness," in particular with regard to the research that focuses on advertising. In many cases, these studies designate those aged 50-55 years and above as "older adults" (e.g. Baumann \& de Laat 2012; Carrigan \& Szmigin 2000; Chen 2015; de Luce 2001; Robinson et al. 2003). This age frame is mentioned several times as being in accordance with conventions established by the advertising industry (e.g. Lee et al. 2007; Prieler et al. 2011). However, others, while using the same measure, note that there is a lack of consistency in relation to how different studies define what "older" means (Simcock \& Lynn 2006). One advertisement-related study draws the line at 65+ (Peterson \& Sautter 2003). Studies of other types of media texts do not have any industry conventions to refer to when 
seeking to define the group under study and must therefore construct their subjects based on other, more ad hoc criteria. Retirement, for example, is sometimes used as a demarcation (Rudmann 2006). Other studies establish "old age" as setting in at some point between 60 and 65 years (Shary 2014), or even as young as 50 years (Lewis et al. 2011), depending on the topic of the article.

While chronological age often guides the distinctions made between older adults and other age groups, in most cases, the exact age of the people portrayed in media is not known (cf. Markson \& Taylor 2000). Hence, other markers of oldness are needed in order to gauge the age of subjects, for example, for content analyses. In most cases, appearance and activities are assessed as indications of chronological age. However, by no means, all of the research makes the criteria for these assessments clear (e.g. Carrigan \& Szmigin 2000; Chen 2015; de-Andrés-del Campo \& de-Lima-Maestro 2014; Kessler et al. 2004; Lauzen \& Dozier 2005). Some studies do discuss the criteria for assessment explicitly (e.g. Bessendorf \& Del Piore 2007; Danowski \& Robinson 2012; Lewis et al. 2011). These typically take the form of everyday or common-sense criteria for marking out someone as old in the Western world:

As in previous studies (Robinson et al. 1995; Swayne \& Greco 1987), people were classified as elderly based on the appearance of a combination of factors such as grey hair, wrinkled faces and hands, retirement scenarios, ambulatory aids such as canes, walkers and wheelchairs, presence of middle-aged children, and/or presence of grandchildren. The appearance of a single factor was not necessarily sufficient to classify an individual as elderly. (Miller et al. 2004: 324)

As becomes evident here, although the chronological measurement itself may seem to be unambiguous and objective, it is based on a number of culturally established understandings about what it means to be "old." While these understandings are shared between coders, as established in tests of intercoder reliability, this does not make us any the wiser as to which underlying assumptions inform them. Likewise, even when criteria for assessment are made explicit, the assumptions about ageing and older age underlying these are seldom acknowledged or discussed. This lack of reflexivity about age categorisations easily leads to the reproduction and reinforcement of existing stereotypes 
International Journal of Ageing and Later Life

or discourses, despite the intention to highlight and, perhaps, even question them:

[...] many authors adopt age categorization strategies which result in characters being labelled as "old" at a variety of actual chronological ages, but in ways which stereotype the ageing process and establish normalizing attributes of behaviour attached to the label of elderliness. (Pike 2013: 83)

The failure to theorise and reflect about age and age categorisations therefore paradoxically means that many studies problematise media depictions while failing to be reflexive about their own constructions.

Articles that openly problematise the notions of ageing and old age usually begin by recognising the difficulty in establishing any well-defined meanings of those terms. Their focus is therefore on the ways in which various imaginaries of ageing and old age are used and enacted in media. Here, analysis conducted from an interactionism perspective is common. For example, by applying an interactional perspective to the literary images of ageing and old age, Pike (2013) is able to demonstrate the ways in which the label of "old" is attributed to different chronological ages. The flexibility and malleability of age categories recurs as an important theme in other studies, including Poulios' (2009) analysis of interactions in a Greek TV reality show and Raisborough's (2014) study of TV makeover shows. The authors emphasise, however, that regardless of the degree of creativity when using various age categories, old age is most often associated with wrongness, ugliness (Raisborough 2014), and poor health (Weber 2012). Such an understanding of old age also seems to underpin media efforts designed to fight negative images. In her analysis of Swedish educational TV programmes created to counteract ageism, Wallander (2013) demonstrates the persistence of age boundaries and images of old age as something requiring an intervention in order to be accepted and regarded as "normal."

In addition to creating space for a more critical approach to the societal ways of understanding ageing and old age, studies problematising those concepts also shed light on the associated phenomena that play a vital role in maintaining stereotypical imaginaries. Weicht (2013), for example, highlights the problematic fixation of contemporary societies on the concept of independence. Analysing both newspaper articles and 
Ageing, old age and media

focus groups, he reveals the ways in which the simplistic understanding of independence as good and dependence as bad is transferred onto old bodies who become markers of dependency, and thus of otherness. Similarly, ageing bodies become markers of ugliness and decline. While Benbow-Buitenhuis (2014) discusses the concept of beauty culture that offers prescribed images of beauty associated with youthfulness, Addison (2005), in her analysis of the Hollywood film industry, discusses the prevalent cult of youth in our society, which is enacted, among other ways, via the celebration of youthful deaths of celebrities such as James Dean. Similarly, Goltz (2007), analysing the gay magazine Instinct, emphasises the role of youthist ideologies in constructing images of old age as fearful and unattractive. These discussions address the very contextual medial constructions of old age that are created in opposition to non-old ideals. In a study of newspaper discourse regarding the ageing population, Lundgren and Ljuslinder (2011) argue that an ageing population functions as a type of empty signifier to which diverse meanings and content can be attributed. As a body of research, the critically oriented studies on ageing, old age and media demonstrate that old age is one such empty signifier which, though constantly filled with new meanings, will never be full.

Several of the reviewed articles take a life course perspective to highlight the changing logics applied by media to people of different ages. These (mainly individual) case studies provide an interesting departure from the typical literature on ageing and media. Following the career development of well-known sportsmen (Atkinson \& Herro 2012), actors (Holmund 2010), actresses (Carman 2012; Brown 2012; Jeremyn 2011, 2012; Krainitzki 2014), film directors (Cohen-Shalev \& Marcus 2008; Cohen-Shalev \& Raz 2008) and singers (Gorton \& Garde-Hansen 2013), these studies trace the way in which various media outlets articulate the appropriateness of ageing processes. For example, Atkinson and Herro (2012), discussing the media coverage of the renowned tennis player Andre Agassi and his career, evidence the ways in which age is used as a frame to judge Agassi's performance and how the tone of media coverage of the same person has changed in response to the changing age of the tennis player. At the beginning of his career, in his early 20s, Agassi was arguably "too young" for his success, while at the end of it, when aged 35, he was "too old." 
International Journal of Ageing and Later Life

\section{Constructing Knowledge about Media}

The role and importance of media in contemporary societies and cultures is widely recognised and acknowledged in the majority of studies. Media is considered an important site of study that offers insights into societal views and norms regarding ageing (e.g. Anderson \& Han 2008; Fealy et al. 2012; Wada et al. 2015) and simultaneously affects people's perception of ageing and old age (e.g. Danowski \& Robinson 2012; Redding 2014; Vandenberg et al. 2012; Wada et al. 2015). Media texts, institutions and technologies are typically regarded as key to the spreading and upholding of stereotypical images and views (Lepianka 2015; Rozanova et al. 2006; Williams et al. 2010). For example, in a series of articles, Robinson and co-authors (Danowski \& Robinson 2012; Robinson \& Anderson 2006; Robinson et al. 2007, 2009) attribute great importance to media with regard to the formation of the stereotypical views of older adults held by children and teenagers:

\footnotetext{
While these stereotypes arise in part from children's direct experience with older individuals, the media serves an important socializing function for many children, supplying them with images that can form, change, and reinforce stereotypes. Gerbner, Gross, Morgan, Signorelli, and Shanahan (2002: 51-52) found that heavy viewers of television are more likely to feel that older people are vanishing from the population, that "there are fewer of them, that they are in worse health, and that they don't live long." Children who are exposed to these stereotypical portrayals of older individuals may develop distorted views of how older individuals really are in society. (Robinson et al. 2007: 203)
}

Often, a clear and powerful negative effect of media is presumed (e.g. Robinson et al. 2003; Uotila et al. 2011; Wolburg 2011). For example, mass media is described as the cause of "the moral indifference and legal ignorance, social nihilism and senseless aggression and cruelty that have become daily realities of our life" (Puchkov 2011: 27) and is regarded as a distorter of reality with an "enormous influence" on individuals (Payne et al. 2008: 268). Although a number of articles seem to implicitly subscribe to a media effect theory, this is rarely explicitly acknowledged or discussed. The article by Raman et al. (2008) is an exception in this regard. In explaining the focus of their study on a comparison of media representations of older people in the USA and India, they actively engage with media effect theories, including those of social cognition and cultivation. 
Other authors problematise the relationship between media and audience in order to emphasise the interactive process between them. This approach leads to studies that examine not only the content but also the reception of various media messages. For example, Chan and Leung (2005), analysing focus groups of older women in Hong Kong, demonstrate the ways in which these women use their different subjectivities to negotiate and respond to the same media content. Critical thinking is therefore emphasised as crucial in both media production and consumption by people of different ages (Cohen 2002; Donlon et al. 2005). Although still emphasising the role of media, these studies seek to bring to light the perspective of the audience who may appropriate the same media content differently. In a similar vein, Blakeborough (2008), analysing depictions of ageing in the TV show The Simpsons on the basis of the concept of ironic parody, argues that the condensation of negative images, rather than perpetuating stereotypes "takes representations, highlights the contradictions, the processes of production, and calls attention to them, asking for a critique" (p.60). This is, however, conditional upon the viewers' competence and knowledge. These few studies therefore offer a slight departure from the picture of the overpowering role of media, instead activating the role of the audience and problematising diverse readings of similar media messages.

The perspective of media as an overpowering force that contributes to discrimination and stereotyping based on age is not the only one in the research analysed here. At the other end of the spectrum, we find several studies that highlight the role of performing arts in reducing stigmatised visions and enabling inner creativity to project richer and more nuanced images. Analysing the images of ageing and old age in a Chinese movie Riding alone for thousands of miles, Stewart (2015: 31) argues:

Film is a cultural storyteller, historical and futuristic at once, activating an imaginary reality between viewer and screen that creates as it informs. To seek the Elder Hero in film and in our lives is to seek a myth of transformation for years of life barely lived by humankind.

What is projected is the artistic element of media texts and it is precisely this element that is deemed to endow media with the potential to 
International Journal of Ageing and Later Life

change dominant, simplified images of ageing and old age. For example, Casado-Gual (2015) and Chivers (2013) demonstrate the creative force of film and literature, documentaries and photographs in forging diversified and complex images of dementia, old age and care. Gravange (2013) calls that untapped potential of media "the magic." Analysing the film Strangers in Good Company, she argues that film as an artistic form may go beyond real life and enable these new ways of thinking and imagining ageing, old age and time. By distorting the view of media as a societal window and mirror, this body of research emphasises the "unreal" aspect of media and its potential.

Several studies included in our review provide new perspectives for discussing the relationship between the lived life and media representations, thus questioning simplified understandings of the separation of media representations and "real life." Hofer (2013), studying one of von Trier's movies on time, proposes the perspective of blurred boundaries to explain the links between fictional characters and the actors' physical age. Working from the perspective of linked lives, Harrington and Brothers (2010) call a similar phenomenon "textistence" to emphasise the merger of fictional and real-life stories. Creativity, and its potential, is what seems to bridge the two, and what offers a resource for reimaging ageing. Also, Chivers (2006), analysing popular films, emphasises the ways in which offstage and onstage characters merge and act through each other, enabling media texts to become a medium of transformation. In her appraisal of Moore's poetry, Gregory (2012) arrives at similar conclusions. She demonstrates the ways in which the creativity of the poet and the content of her work change over time. As Gregory (2012) argues, an exploration of new themes and styles of writing becomes possible thanks to Moore's embracement of her own age. In a similar vein, Cohen-Shalev and Marcus (2008), with their study of the work of the film director Claude Saute, and Cohen-Shalev and Raz (2008) with their analysis of the films and career of Akira Kurosowa, demonstrate the changing style and content of the produced movies. The paradox of invoking new images of ageing lies therefore in the ability of artists to perform according to their own age. The separation between media and lived life is therefore called into question. 
Ageing, old age and media

\section{Constructing Knowledge about Problematic Representations}

Once research begins to address the overall question of the media representations of older adults, the issue of under- or misrepresentation is not far removed:

If we were to draw a picture of American life exclusively from evidence derived from these thirty-one magazines, we would have to conclude that the consuming population consists primarily of people 18 to 49 years old. We would also have to conclude that there are almost no people of color in the United States. [...] In general, older men and women appear as survivors of cancer, as patients with cancer. They suffer memory loss, hearing loss, hair loss and loss of sexual vigor. (de Luce 2001: 41)

Almost a quarter of the articles under review (48/186) are concerned with these topics. Most of the articles discuss both the relative visibility or under-representation of older adults in different types of media texts and the ways in which they are depicted in terms of either stereotypes or particular roles. Although some of the articles that discuss stereotypification or role prominence do not address the question of under-representation, the topics are considered to form a single theme because the former and the latter go hand-in-hand in the majority of cases.

The widespread under-representation of older adults is implicitly or explicitly regarded as ageist by some studies (e.g. Carrigan \& Szmigin 2000; Clarke et al. 2014; de Luce 2001; Lepianka 2015; Lewis et al. 2011), that is, as discriminating against a group of people due to chronological and/or social age (Bytheway 2005; Iversen et al. 2009; Palmore 1999). This discrimination is presented both as a problem in itself, that is, as a form of injustice, and often also as a problematic rendering of reality that is likely to affect audience's beliefs of and understandings about the world. While often not directly argued, several of the studies seem to follow the reasoning that the under-representation of older adults within both factual and fictional genres is problematic because it does not give an accurate account of reality and this, in turn, leads people to form incorrect or problematic understandings of the world (e.g. de Luce 2001; Kessler et al. 2004; Lauzen \& Dozier 2005; Robinson \& Anderson 2006; Signorelli 2001). Other articles regard media texts as co-constructors of social realities and critique the ways in which the truths and norms that are being presented via media silence, stigmatise or glamorise (particular groups of) older 
International Journal of Ageing and Later Life

adults (e.g. Harwood \& Anderson 2002; Low \& Dupuis-Blanchard 2013; Rozanova 2010; Rudmann 2006). Here, under-representation is treated as part of a larger problem, related, for example, to discourses that articulate youth as the norm while rendering old age invisible. In addition, a few articles touch upon an entirely different issue, namely that businesses may be missing a golden opportunity to reach an attractive target group, either because they are not sufficiently aware of the spending powers of older adults or because they may fail to attract older adults if they present them in a negative light in advertisements (e.g. de Luce 2001; Lee et al. 2006; Williams et al. 2010). In these cases, it is suggested that a more positive depiction of older adults in advertisements would be a successful business strategy.

In general, the role of media in studies that focus on the underrepresentation and/or misrepresentation of ageing and old age is portrayed as "window on the world," which may present reality more or less accurately, implying that reality is fixed and objective given. Hence, incorrect media portrayals are presumed to give rise to distorted views of reality. For example, research on roles assigned to older characters in media regards such media representations as either shaping the audience's understandings of the world (Danowski \& Robinson 2012; Prieler et al. 2015; Signorelli 2001, 2004; Towbin et al. 2003) or as expressions of existing understandings (Zhang et al. 2008), and often both (Chan \& Leung 2005; Markson \& Taylor 2000; Raman et al. 2008). This leads many scholars to suggest that the increased visibility of older adults and old age in media will solve the problem of unjust representations.

One of the biggest problems with mis- and under-representations of older adults and old age in media as recognised in the analysed articles is that of gendered images. Almost a quarter of the articles explicitly address the question of gender and gendered representations of ageing and old age. These studies typically begin by recognising the socially and culturally constructed character of both age and gender. More than any other sub-group, articles belonging to this group apply critical and feminist perspectives in their analysis. In this case, the question of gender is presented as important for understanding the processes and images of ageing, and the phenomenon of gendered ageing is recognised as equally relevant for men and women, though in different ways (Calasanti 2007; 
Ageing, old age and media

Pritchard \& Whiting 2015; Wilińska 2010). Analyses of the careers of female comedians by Mock (2012) and the actress Judi Dench by Krainitzki (2014) provide authors with the basis to discuss the potential of acting upon age and gender stereotypes, stepping outside them and challenging them. This is in line with Harpin's (2012) reading of several British theatre plays that feature older women, where the presence of older women and their voices on stage are seen as a sign of change. Unintentionally, however, these studies individualise the issue of gendered representation by calling for physically old female bodies to act on their own behalf to change age and gender stereotypes, thereby shifting the responsibility for changing attitudes to ageing and old age away from society at large.

Similar conclusions are drawn from studies that explore older masculinities in media. The presence of older men and their ability to act upon cultural scripts of older masculinities are identified as signs of change and hope. This is especially the case when a clear shift or transformation of an actor or a producer is highlighted. Redding (2014), for example, highlights here some of Clint Eastwood's recent productions, in which the ageing actor and producer opens himself up for exploring typically taboo topics of weakness and vulnerability in men. Here, the contrast with earlier productions by and with the same actor constitutes an important line of argument to support the main claim about forging new images of older masculinities. Also, by contrasting with earlier productions of American Westerns as a film genre, Saxton and Cole (2013) argue that the value of the book and movie No Country for Old Men is their reinvention of ageing masculinities. Here, the key attributes of the main protagonist are discussed by authors with references made to how different they are from what is typically considered as male characteristics. The article admires the focus on reflection, life review and questioning as new to images of masculinity, but it does not address the question of how these qualities can be attributed to cultural expectations regarding old age as a time of deeper contemplation.

While much of the research cited above suggests that the use of negative and stereotypical depictions is very harmful for other age groups' perception of older adults as well as for the identity formation and selfperception of older adults themselves, Low and Dupuis-Blanchard (2013) discuss the use of mainly and overtly positive representations, which are 
International Journal of Ageing and Later Life

also problematic. Firstly, they stress that older adults are, in fact, being presented in more diverse and positive ways than previously. However, this does not mean that all is well. In their analysis of Zoomer Magazine, a Canadian magazine aimed at older adults, Low and Dupuis-Blanchard find almost no images of older adults of colour, of very old people or of poor older adults. Instead, most of the imagery seems to portray happy, good-looking, affluent Caucasians of a certain age:

These positive images therefore are problematic as they do not account for the diversity of seniors in society. Instead they reflect anti-ageing ethos that is ageist in its devaluing of old age and are decidedly class bound. In them the only truly positive aging is anti-aging. (Low \& Dupuis-Blanchard 2013: 61)

The increase in much more positive portrayals of older adults, according to Low and Dupuis-Blanchard, does not solve the representational problem, it merely causes a new one to emerge, namely, the exclusion of older adults, who for various reasons do not see themselves reflected in the glamorous images of todays "golden oldies." What is needed, instead, is maximum variety in depictions across all the dimensions of gender, ethnicity, affluence, life style and cultures. This is in line with the argument presented by Sciplino et al. (2010) who note that the depiction of grandparents in children's books from various countries is surprisingly homogenous and could benefit from showing a much larger variety in terms of looks, activities and positions.

\section{Discussion and Conclusion}

When embarking on this study, we wanted to examine the ways in which existing research addresses the question of media and old age. In doing so, we began with two major assumptions: the importance of media to old age and the importance of research on old age as a distinct life phase. None of these assumptions is unproblematic, however. In the course of reviewing other research, we therefore turned to our own understandings to reflect and revise our questions and, ultimately, to pose new ones. Following Baumeister and Levy's (1997: 314) contention that literature reviewers should remain open to new perspectives "to allow themselves to be led by the evidence," we too direct our 
efforts at taking additional steps in order to discuss the results of this literature review.

Unquestionably, the articles under review have been of great importance in terms of solidifying a rather neglected topic of research, that of the media representations of older adults, as well as empirically documenting beginning or continuing change. However, what remains problematic in much of the literature reviewed here is the insistence on the use of simplified understandings of the very core concepts: old age and media. The interdisciplinary nature of the research is probably a key factor here, and we cannot stress enough the importance of explicitly acknowledging the complexity of both concepts. Thus, an important insight that arises from our study is the existence of fairly stable disciplinary boundaries even when approaching highly transdisciplinary research problems. This largely refers to the visible discrepancy between media studies and ageing studies, which, on the basis of this review, seldom seem to engage in dialogue and knowledge exchange (for recent efforts to do so, see, e.g., Blaakilde et al. 2017; Christensen \& Jerslev 2017; Christensen \& Petersen 2017). As demonstrated here, both ageing and media are highly complex phenomena and the transdisciplinary scrutiny of the two therefore requires much more dialogue between disciplines as well as heightened reflexivity.

To a large extent, media is repeatedly portrayed as an independent, external actor that has a considerable influence on how societies think, feel and act. We are not claiming that media technologies, texts and institutions do not affect people and society in a variety of ways, but rather than this tends to happen in more subtle, overarching and structural ways - for instance, in the form of mediatisation (Hepp \& Krotz 2014; Lundby 2014) or the co-construction of discourses and practices (Couldry 2009) - than the one-to-one effect that is often assumed. Moreover, the logics that inform media production and consumption are not only about the dynamics that emerge from within the media industry or technological materialities but are equally an expression of audiences' practices, hopes and fears (Altheide 2013; van Dijck \& Poell 2013). With this in mind, we therefore propose turning to more nuanced perspectives on media that recognise the interactive processes involved in its creation and reception. There has been a gradual increase in efforts to do this (e.g. Christensen \& 
International Journal of Ageing and Later Life

Jerslev 2017; Fernández-Ardèvol et al. 2017; Ferris-Taylor et al. 2019; Loos et al. 2018; Wilińska et al. 2018). These efforts have so far triggered several new research initiatives, such as the project Ageing + Communication + Technologies (ACT), Concordia University, Canada (http://actproject.ca/); the research centre for Women, Ageing and Media (WAM), University of Gloucestershire, UK; the research project Ageing and old age in the media and elderly people's media, University of Copenhagen, Denmark; as well as the Media and Ageism working group that is part of the COST action Ageism: A multi-national, interdisciplinary perspective (http://notoageism. com). Initiatives such as these enable scholars from both Gerontological disciplines and Media and Communication Studies to enter into fruitful dialogue and joint projects, learning about the complexities of their respective topics from each other. By taking an interactive approach, such projects forge the way forward not only in terms of understanding both fields, but importantly, changing the ways in which ageing and media are portrayed as well as developing creative solutions that challenge stereotypes and encourage new media practices.

Old age, though often recognised as socially and culturally constructed, is still pinpointed as a "special" category that merits particular attention. Not surprisingly, the reviewed articles conclude either by critiquing media for silencing old age or for presenting it in ways that are either too positive or too negative. What needs to be questioned is the very effort of trying to represent old age. How can a relational and socially constructed category be represented in the most fruitful way? For example, our findings point out that one of the most common ways of establishing the inclusion criteria for media analysis of old age is physical signs of ageing, such as wrinkles and grey hair. In such approaches, the merging of biological markers with social judgements leaves very little space for questioning the very focus on age segments as a central and natural object of knowledge. Similarly, age groupbased research causes the same problems with regard to the one-sided views of media as an overpowering external force: age boundaries and groups are not only maintained but also reinforced with new evidence by such research.

Kohli (1985) regards this Western fixation on ageing and age segments as a fairly recent way of ordering and understanding life, which emerged with the mindset of modernity (see also Spariosu 2016). It is the understanding of human life as ordered into well-defined sections that each 
Ageing, old age and media

have their designated challenges and duties what Kohli terms chronologisation. He argues that the modern understanding of old age is a product of several developments that emerged during and after the renaissance period. Examples include increased age-uniformity in life events such as marriage and death, the rise of the modern working life in the factory rather than in the family, as well as the need of the modern state to easily and rationally tally and handle its citizens. He also asserts:

Chronological age is apparently a very good criterion for the rational organization of public services and transfers. It renders the life course - and, the passage of the individual through social systems - orderly and calculable. (Kohli 1985: 286-287)

Apart from rendering the life course calculable, which is useful in many ways both for the modern state and capitalist society, Kohli also regards the fixation on chronological age as a socialising device in a society that has become increasingly individualistic and freed from the boundaries of religion, family bonds and the local community (Kohli 1985). While it can be argued that current society is already post-chronological (Blaakilde 2004), it is evident from our review that the chronologisation paradigm still dominates in most research on media representation of old age. Thus, it is not "old" that constitutes the main problem, but the ways that we as citizens, public servants and scholars have learnt to categorise, calculate and evaluate age. Thus, to address the problem of "old," we have toaddress the ways in which age is made relevant, important and visible. In this, "old age" as a problem is just the tip of an iceberg called "age." Seen in that light, we urge current research into the relationship between media and old age not only to build on the foundations that have been laid, but also to start questioning them by asking the underlying and more difficult questions such as the following: What is it that sets old age apart or, perhaps, why does ageing cause such fear in Western societies? Moreover, how does a chronologised world view affect media texts, institutions and audiences, and how can it be challenged in research on ageing and media?

\section{Acknowledgements}

The authors thank Line Nybro Pedersen and the anonymous reviewers for their helpful feedback on an earlier version of this article. 
International Journal of Ageing and Later Life

\section{Corresponding Author}

Monika Wilińska, School of Health and Welfare, Jönköping University, Box 1016, 55111 Jönköping, Sweden. Email: monika.wilinska@ju.se.

\section{References}

Aday, R. \& Austin, B. (2000). Images of aging in the lyrics of American country music. Educational Gerontology 26(2): 135-154.

Addison, H. (2005). Transcending time: Jean Harlow and Hollywood's narrative of decline. Journal of Film and Video 57(4): 32-46.

Altheide, D. (2013). Media logic, social control, and fear. Communication Theory 23(3): 223-238.

Anderson, K. A. \& Han, J. (2008). An exploration of ageism and sexism in obituary photographs: 1967-1997. Omega: Journal Of Death \& Dying 58(4): 335-345.

Atkinson, J. L. \& Herro, S. K. (2010). From the chartreuse kid to the wise old gnome of tennis: Age stereotypes as frames describing Andre Agassi at the U.S. Open. Journal of Sport \& Social Issues 34(1): 86-104.

Bacchi, C. L. (2005). Discourse, discourse everywhere: Subject "agency" in feminist discourse methodology. Nordic Journal of Women's Studies 13(3): 198-209.

Bai, X. (2014). Images of ageing in society: A literature review. Journal of Population Ageing 7(3): 231-253.

Baumann, S. \& de Laat, K. (2012). Socially defunct: A comparative analysis of the underrepresentation of older women in advertising. Poetics 40(6): 514-541.

Baumeister, R. F. \& Leary, M. R. (1997). Writing narrative literature reviews. Review of General Psychology 1(3): 311-320.

Benbow-Buitenhuis, A. (2014). A feminine double-bind? Towards understanding the commercialisation of beauty through examining antiageing culture. Social Alternatives 33(2): 43-49.

Berger, P. L. \& Luckmann, T. (1989). The social construction of reality: A treatise in the sociology of knowledge. London, UK: Penguin Books. Original published 1966.

Bessendorf, G. \& Del Piore, R. (2007). Women, weight, and age: Social comparison to magazine images across the lifespan. Sex Roles 563(4): 215-222. 
Blaakilde, A. L. (2004). Løber tiden fra Kronos? Om kronologiseringens betydning for forestillinger om alder [Does time run for Chronos? The impact of chronologization on the understanding of age]. Tidsskrift for Kulturforskning [Journal for Cultural Studies] 3(1): 67-85.

Blaakilde, A. L., Iversen, S. M. \& Wilińska, M. (2017). Growing old with and via media. MedieKultur 33(63): 1-8.

Blakeborough, D. (2008). "Old people are useless": Representations of aging on The Simpsons. Canadian Journal On Aging 27(1): 57-67.

Brown, W. (2012). Channel hopping: Charlotte Rampling in French cinema of the early 2000s. Celebrity Studies 3(1): 52-63.

Burr, V. (2007). Social Constructionism (2nd ed.). London: Routledge.

Bytheway, B. (2005). Ageism and age categorization. Journal of Social Issues 61(2): 361-374.

Calasanti, T. (2007). Bodacious berry, potency wood and the aging monster: Gender and age relations in anti-aging ads. Social Forces 86(1): 335-355.

Carman, E. (2012). "Women rule Hollywood": Ageing and freelance stardom in the studio system. Celebrity Studies 3(1): 13-24.

Carrigan, M. \& Szmigin, I. (2000). Advertising and older consumers: Image and ageism. Business Ethics: A European Review 9(1): 42-50.

Casado-Gual, N. (2015). Unexpected turns in lifelong sentimental journeys: Redefining love, memory and old age through Alice Munro's "The Bear Came Over the Mountain" and its film adaptation Away from Her. Ageing and Society 35(2): 389-404.

Chan, S. H. \& Leung, L. C. (2005). Between viewing and consuming: How aging women in Hong Kong negotiate television advertisements. Feminist Media Studies 5(2): 123-140.

Chen, C. H. (2015). Advertising representations of older people in the United Kingdom and Taiwan: A comparative analysis. The International Journal of Aging and Human Development 80(2): 140-183.

Chivers, S. (2006). Baby Jane grew up: The dramatic intersection of age with disability. Canadian Review of American Studies 36(2): 211-228.

Chivers, S. (2013). Reimagining care: Images of aging and creativity in House Calls and Year at Sherbrooke. International Journal of Ageing and Later Life 7(2): 53-71. 
International Journal of Ageing and Later Life

Christensen, C. \& Jerslev, A. (eds) (2017). Ælldre Mennesker i et Mediesamfund [Older Adults in a Media Society]. Copenhagen, DK: Frydenlund Academic.

Christensen, C. \& Petersen, L. N. (2017). Introduction: Being old in the age of mediatization. Nordicom Review 38(1): 9-25.

Clarke, L. H., Bennett, E. V. \& Liu, C. (2014). Aging and masculinity: Portrayals in men's magazines. Journal of Aging Studies 31: 26-33.

Cohen, H. L. (2002). Developing media literacy skills to challenge television's portrayal of older women. Educational Gerontology 28(7): 599-620.

Cohen, L. (1992). No aging in India: The uses of gerontology. Culture, Medicine and Psychiatry 16(2): 123-161.

Cohen-Shalev, A. \& Marcus, E. L. (2008). Claude Sautet's winter of discontent: The aging of a moviemaker. Psychology of Aesthetics, Creativity, and the Arts 2(4): 213-220.

Cohen-Shalev, A. \& Raz, A. (2008). Poetry of unadulterated imagination: The late style of Akira Kurosawa. Psychology of Aesthetics, Creativity, and the Arts 2(1): 34-41.

Couldry, N. (2009). Theorising media as practice. Social Semiotics 14(2): 115-132.

Cruikshank, M. (2003). Learning to be old. Gender, culture and ageing. Oxford: Rowman \& Littlefield Publishers.

Danowski, J. \& Robinson, T. (2012). The portrayal of older characters in popular children's picture books in the US. Journal of Children and Media 63(3): 33-50.

de-Andrés-del Campo, S. \& de-Lima-Maestro, R. (2014). Critical analysis of government vs. commercial advertising discourse on older persons in Spain. Comunicar 21(42): 189-197.

de Luce, J. (2001). Silence at the newsstand. Generations 25(3): 39-43.

Donlon, M., Ashman, O. \& Levy, B. (2005). Re-vision of older television characters: A stereotype-awareness intervention. Journal of Social Issues 61(2): 307-319.

Douglas, W. \& Buck, S. (2009). Television and the elderly in the United States. In B. Schorb, A. Hartung \& W. Reißmann (eds.) Medien und höheres Lebensalter (pp. 303-315). Wiesbaden, DE: VS Verlag für Sozialwissenschaften. 
Estrada, M., Moliner, M. \& Sánches, J. (2010). Attitudes towards advertisements of the older adults. International Journal of Aging and Human Development 70(3): 231-249.

Fealy, G., McNamara, M., Tracy, M. P. \& Lyons, I. (2012). Constructing ageing and age identities: A case study of newspaper discourses. Ageing and Society 32(1): 85-102.

Fernández-Ardèvol, M., Sawchuk, K. \& Grenier, L. (2017). Maintaining connections: Octo- and nonagenarians on digital "use and non-use." Nordicom Review 38(1): 39-51.

Ferris-Taylor, R. J. G., Grist, H., Jennings, R., Rosselson, R. \& Wiseman, S. (2019). Reading film with age through collaborative autoethnography: Old age and care, encounters with Amour (Haneke, 2012), Chronic (Franco, 2015) and A Woman's Tale (Cox, 1991). Life Writing 16(1): 69-95.

Goltz, D. (2007). Laughing at absence: Instinct Magazine and the hypermasculine gay future? Western Journal of Communication 71(2): 93-113.

Gorton, K. \& Garde-Hansen, J. (2013). From old media whore to new media troll. Feminist Media Studies 13(2): 288-302.

Gravange, P. H. (2013). The magic of cinema: Time as becoming in strangers in good company. International Journal Of Ageing \& Later Life 8(1): 41-63.

Green, B. S. (1993). Gerontology and the Construction of Old Age: A Study in Discourse Analysis. New York: Aldine de Gruyter.

Gregory, E. (2012). "Still leafing": Celebrity, confession, Marianne Moore's "The Camperdown Elm" and the scandal of age. Journal of Modern Literature 35(3): 51-76.

Gullette, M. M. (2004). Aged by Culture. Chicago, IL: The University of Chicago Press.

Haraway, D. J. (1991). Simians, Cyborgs, and Women. The Reinvention of Nature. New York: Routledge

Harpin, A. (2012). The lives of our mad mothers: Aging and contemporary performance. Women \& Performance: A Journal of Feminist Theory 22(1): 67-87.

Harrington, C. \& Brothers, D. (2010). A life course built for two: Acting, aging, and soap operas. Journal of Aging Studies 24(1): 20-29.

Harwood, J. \& Anderson, K. (2002). The presence and portrayal of social groups on prime-time television. Communication Reports 15(2): 81-97. 
International Journal of Ageing and Later Life

Hazan, H. (1994). Old Age: Constructions and Deconstructions. Cambridge: Cambridge University Press.

Hepp, A. \& Krotz, F. (eds.) (2014). Mediatized Worlds: Culture and Society in a Media Age. New York: Palgrave Macmillan.

Hine, R. (2011). In the margins: The impact of sexualized images on the mental health of ageing women. Sex Roles 657(8): 632-646.

Hofer, R. (2013). Framing the march of time: Lars von Trier's dimension. Scandinavia 52(1): 125-140.

Holmlund, C. (2010). Celebrity, ageing and Jackie Chan: Middle-aged Asian in transnational action. Celebrity Studies 1(1): 96-112.

Howarth, D. (2000). Discourse. Buckingham: Open University Press.

Iversen, T., Larsen, L. \& Solem, P. (2009). A conceptual analysis of ageism. Nordic Psychology 61(3): 4-22.

Jermyn, D. (2011). Unlikely heroines?' Women of a certain age' and romantic comedy. CineAction (85): 26.

Jermyn, D. (2012). 'Glorious, glamorous and that old standby, amorous': The late blossoming of Diane Keaton's romantic comedy career. Celebrity Studies 3(1): 37-51.

Jones, K. (2004). Mission drift in qualitative research, or moving toward a systematic review of qualitative studies, moving back to a more systematic narrative review. The Qualitative Report 9(1): 94-111.

Jørgensen, M. \& Phillips, L. (2010). Discourse Analysis as Theory and Method. London: Sage.

Katz, S. (1996). Disciplining Old Age: The Formation of Gerontological Knowledge. Charlottesville, VI: University Press of Virginia.

Kessler, W., Rakoczy, K. \& Staudinger, U. (2004). The portrayal of older people in prime-time television series: The match with gerontological evidence. Ageing and Society 24(4): 531-552.

Kohli, M. (1985). The world we forgot: A historical review of the life course. In V. W. Marshall (ed.) Later Life: The Social Psychology of Aging (pp. 271-303). Beverly Hills, CA: Sage.

Krainitzki, E. (2014). Judi Dench's age-inappropriateness and the role of M: Challenging normative temporality. Journal of Aging Studies 29(1): 32-40.

Lauzen, M. \& Dozier, D. (2005). Maintaining the double standard: Portrayals of age and gender in popular films. Sex Roles 52(7-8): 437-446. 
Lee, B., Kim, B. \& Han, S. (2006). The portrayal of older people in television advertisments: A cross-cultural content analysis of the United States and South Korea International Journal of Aging and Human Development 63(4): 279-297.

Lee, M., Carpenter, B. \& Meyers, L. (2007). Representations of older adults in television advertisements. Journal of Aging Studies 21(1): 23-30.

Lepianka, D. A. (2015). How similar, how different? On Dutch media depictions of older and younger people. Ageing and Society 35(5): 1095-1113.

Lewis, D. C., Medvedev, K. \& Seponski, D. M. (2011). Awakening to the desires of older women: Deconstructing ageism within fashion magazines. Journal of Aging Studies 25(2): 101-109.

Loos, E., Nimrod, G. \& Fernández-Ardèvol, M. (2018). Older Audiences in the Digital Media Environment: A Cross-National Longitudinal Study. Montreal: ACT Project. Available on http://spectrum.library. concordia.ca/983866/ (Accessed March 15, 2019).

Low, J. \& Dupuis-Blanchard, S. (2013). From zoomers to geezerade: Representations of the aging body in ageist and consumerist society. Societies 3(1): 55-65.

Lundby, K. (ed.) (2014). Mediatization of Communication. Berlin, DE: De Gruyter Mouton.

Lundgren, A. S. \& Ljuslinder, K. (2011). "The baby-boom is over and the ageing shock awaits": Populist media imagery in news-press representations of population ageing. International Journal of Ageing and Later Life 6(2): 39-71.

Lykke, N. (2010). Feminist Studies: A Guide to Intersectional Theory, Method and Writing. New York: Routledge.

Markson, E. \& Taylor, C. (2000). The mirror has two faces. Ageing and Society 20(2): 137-160.

McCarthy, E. D. (1996). Knowledge as Culture: The New Sociology of Knowledge. London: Routledge.

Miller, D., Leyell, T. \& Mazachek, J. (2004). Stereotypes of the elderly in U.S. television commercials from the 1950s to the 1990s. International Journal of Aging and Human Development 58(4): 315-340.

Mock, R. (2012). Stand-up comedy and the legacy of the mature vagina. Women \& Performance: A Journal of Feminist Theory 22(1): 9-28. 
International Journal of Ageing and Later Life

Palmore, E. B. (1999). Ageism: Negative and Positive. New York: Springer Publishing Company.

Pascale, C. M. (2011). Cartographies of Knowledge. Exploring Qualitative Epistemologies. Los Angeles, CA: Sage.

Payne, B., Appel, J. \& Kim-Appel, D. (2008). Elder abuse coverage in newspapers: Regional differences and its comparison to child-abuse coverage. Journal of Elder Abuse and Neglect 20(3): 265-275.

Peterson, R. \& Sautter, E. (2003). A review of the depiction of senior citizen instrumental and congenial behavior in television commercials. Journal of Hospitality and Leisure Marketing 101(2): 101-121.

Pike, E. (2013). The role of fiction in misrepresenting later life leisure activities. Leisure Studies 32(1): 69-87.

Poulios, A. (2009). Age categories as an argumentative resource in conflict talk: evidence from a Greek television reality show. International Journal of the Sociology of Language 2009(200): 189-208.

Powell, J. L. (2001). Theorizing social gerontology: The case of old age, professional power and social policy in the United Kingdom. Journal of Aging and Identity 6(3): 117-135.

Powell, J. L. (2006). Social Theory and Aging. Oxford: Rowman and Littlefield Publishers.

Prieler, M., Kohlbacher, F., Hagiwara. S. \& Arima, A. (2011). Gender representation of older people in Japanese television advertisements. Sex Roles 64(5): 405-415.

Prieler, M., Kohlbacher, F., Hagiwara, S. \& Arima, A. (2015). The representation of older people in television advertisements and social change: The case of Japan. Ageing and Society 35(4): 865-887.

Pritchard, K. \& Whiting, R. (2015). Taking stock: A visual analysis of gendered ageing. Gender, Work and Organization 22(5): 510-528.

Puchkov, P. (2011). Spotlight on elder abuse as reported by the Russian mass media. The Journal of Adult Protection 13(1): 27-35.

Raisborough, J. (2014). Stretching middle age: The lessons and labours of active ageing in the makeover show. Media, Culture and Society 36(8): 1069-1083.

Raman, P., Harwood, J., Weis, D., Anderson, J. \& Miller, G. (2008). Portrayals of older adults in U.S. and Indian magazine advertisements: A crosscultural comparison. Howard Journal of Communications 19(3): 221-240. 
Redding, A. (2014). A finish worthy of the start: The poetics of age and masculinity in Clint Eastwood's Gran Turino. Film Criticism 38(3): 1-23.

Robinson, T. \& Anderson, C. (2006). Older characters in children's animated television programs: A content analysis of their portrayal. Journal of Broadcasting and Electronic Media 50(2): 287-304.

Robinson, T., Callister, M. \& Magoffin, D. (2009). Older characters in teen movies from 1980-2006. Educational Gerontology 35(8): 687-711.

Robinson, T., Callister, M., Magoffin, D. \& Moore, J. (2007). The portrayal of older characters in Disney animated films. Journal of Aging Studies 21(3): 203-213.

Robinson, T., Popovich, M., Gustafson, R. \& Faser, C. (2003). Older adults' perception of offensive senior stereotypes in magazine advertisements: Results of a q-methodology analysis. Educational Gerontology 29(6): 503-519.

Rozanova, J. (2010). Discourse of successful aging in The Globe and Mail: Insights from critical gerontology. Journal of Aging Studies 24(4): 213-222.

Rozanova, J., Northcott, H. C. \& McDaniel, S. A. (2006). Seniors and portrayals of intergenerational inequality in The globe and Mail. Canadian Journal of Aging 25(4): 372-386.

Rudmann, D. L. (2006). Shaping the active, autonomous and responsible modern retiree: An analysis of discursive technologies and their links with neo-liberal political rationality. Ageing and Society 26(2): 181-201.

Saxton, B. \& Cole, T. R. (2013). No country for old men: A search for masculinity in later life. International Journal of Ageing and Later Life 7(2): 97-116.

Sciplino, C., Smith, P., Hurme, H., Rusek, M. \& Bäckvik, P. (2010). Representations of grandparents in children's books in Britain, Italy, Greece, Finland, and Poland. Journal of Intergenerational Relationships 8(3): 298-316.

Shary, T. (2014). The politics of aging in the May-December romance plot. Quarterly Review of Film and Video 31(7): 669-678.

Signorelli, N. (2001). Aging on television: The picture of the nineties. Generations 25(3): 34-38.

Signorelli, N. (2004). Aging on television: Messages relating to gender, race, and occupation in prime time. Journal of Broadcasting and Electronic Media 48(2): 279-301. 
International Journal of Ageing and Later Life

Simcock, P. \& Lynn, S. (2006). The invisible majority? Older models in UK television advertising. International Journal of Advertising 25(1): 87-106.

Spariosu, M. (2016). Modernism and exile: Play, liminality, and the exilic-utopian imagination. London: Palgrave Macmillan.

Stewart, J. A. (2015). Seeking the elder hero in Zhang Yimou's film: Riding alone for thousands of miles. Jung Journal: Culture and Psyche 9(3): 31-43.

Syvertsen, T. (2010). Medieforskerne hater gamle mennesker. Norsk Medietidsskrift 17(4): 381-391.

Thorne, S. (2017). Metasynthetic madness: What kind of monster have we created? Qualitative Health Research 27(1): 3-12.

Towbin, M., Haddock, S., Zimmerman, T., Lund, L. \& Tanner, L. (2003). Images of gender, race, age and sexual orientation in Disney feature-length animated films. Journal of Feminist Family Therapy 15(4): 19-44.

Uotila, H., Lumme-Sandt, K. \& Saarenheimo, M. (2011). Lonely older people as a problem in society: Construction in Finnish media. International Journal of Ageing and Later Life 5(2): 103-130.

Vandenberg, A. E., Price, A. E., Friedman, D. B., Marchman, G. \& Anderson, L. A. (2012). How do top cable news websites portray cognition as an aging issue? The Gerontologist 52(3): 367-382.

van Dijck, J. \& Poell, T. (2013). Understanding social media logic. Media and Communication 1(1): 2-14.

van Selm, M. \& Van der Heijden, B. (2014). Media portrayals of older employees: A success story? Journal of Organizational Change Management 27(4): 583-597.

Wada, M., Clarke, L. \& Rozanova, J. (2015). Constructions of sexuality in later life: Analyses of Canadian magazine and newspaper portrayals of online dating. Journal of Aging Studies 32(1): 40-49.

Wallander, K. (2013). Successful images of successful ageing? Representations of vigorous elderly people in a Swedish educational television programme. Nordicom Review 34(1): 91-103.

Weber, B. R. (2012). Reality (celebrity) check: Fat, death and the ageing female body. Celebrity Studies 3(1): 64-77.

Weed, M. (2006). Interpretive qualitative synthesis in the sport and exercise sciences: The meta-interpretation approach. European Journal of Sport Science 6(2) 127-139. 
Weed, M. (2008). A potential method for the interpretive synthesis of qualitative research: Issues in the development of "meta-interpretation." International Journal of Social Research Methodology 11(1): 13-28.

Weicht, B. (2013). The making of "the elderly": Constructing the subject of care. Journal of Aging Studies 27(2): 188-197.

Wilińska, M. (2010). Because women will always be women and men are just growing older: Intersecting discourses of ageing and gender. Current Sociology 58(6): 879-896.

Wilińska, M., de Honeheim, A. \& Anbäcken, E. M. (2018). Ageism in a cross-national perspective: Reflections from the research field. In L. Ayalon \& C. Tesch-Roemer (eds.), Contemporary Perspectices on Ageism (pp. 441-459). Cham, DE: Springer Verlag.

Williams, A., Ylänne, V., Wadleigh, P. \& Chen, C. H. (2010). Portrayals of older adults in UK magazine advertisements: Relevance of target audience. Communications 35(1): 1-27.

Wolburg, J. (2011). Aging gracefully: Emerging issues for public policy and consumer welfare. The Journal of Consumer Affairs 45(3): 365-371.

Zhang, Y., Harwood, J., Williams, A., Ylänne-McEwen, A., Wadleigh, P. \& Thimm, C. (2006). The portrayal of older adults in advertising: A cross-national review. Journal of Language and Social Psychology 25(3): 264-282.

Zhang, Y., Song, Y. \& Carver, L. (2008). Cultural values and aging in Chinese television commercials. Journal of Asian Pacific Communication 18(2): 209-224.

Zordan, D. (2010). Too old for that kind of thing? Sexuality and unshareable desire in Dresen's Cloud 9. Theology and Sexuality 15(3): 283-292. 